\title{
Influence of Vanadium Additions on the Performance of $\mathrm{Mo}_{3} \mathrm{Si}$
}

\author{
I. Rosales-Cadena \\ Center for Research in Engineering and Applied Sciences, Cuernavaca, Mexico \\ Email: faye12@uaem.mx
}

How to cite this paper: Rosales-Cadena, I. (2021) Influence of Vanadium Additions on the Performance of $\mathrm{Mo}_{3} \mathrm{Si}$. Materials Sciences and Applications, 12, 345-352. https://doi.org/10.4236/msa.2021.127023

Received: June 5, 2021

Accepted: July 6, 2021

Published: July 9, 2021

Copyright $\odot 2021$ by author(s) and Scientific Research Publishing Inc. This work is licensed under the Creative Commons Attribution International License (CC BY 4.0).

http://creativecommons.org/licenses/by/4.0/

\begin{abstract}
Several molybdenum silicides based alloys were produced by arc cast method with different vanadium additions. The microstructures revealed mainly single phase in samples with precipitation of second phases segregated to the grain boundaries. Lattice parameter and density measurements with different $\mathrm{V}$ concentrations have been correlated with lattice distortion. Mechanical properties studies were carried out, showing a decreasing behavior in microhardness while fracture toughness value increases at intermediate concentrations. Results indicated that vanadium alloying produces a significant effect on grain growth behavior and second phase precipitation.
\end{abstract}

\section{Keywords}

Silicides, Indentation, Hardness, Fracture Toughness, Lattice Parameter

\section{Introduction}

Alloys produced from molybdenum and silicon have been studied for many years, especially because the resultant intermetallic compounds present good properties under extreme conditions [1] [2]. In particular, good mechanical properties are absent in A-15 structured materials [3] [4] [5], for such reason some authors [6] [7] [8] have investigated this type of intermetallics compounds, evaluating their mechanical properties at room and high temperature as well the room temperature fracture toughness and hardness looking for a possible improvement [9]. Mechanical properties in $\mathrm{V}_{3} \mathrm{Si}$ single crystals at high temperature have been investigated with interesting results showing the effect of the internal defects in crystal lattice [10]. Other molybdenum silicides have been investigated, characterizing mechanical and electrical properties [11]. The importance to consider materials with low density always have been important for applications in spe- 
cific operations, not only because can be used to employ machines with low cost in operation but also with enough mechanical resistance, then the combination with excellent mechanical resistance with good high temperature resistance provides an extra value to the alloys which possess such characteristics [3].

Until now, mechanical and physical properties of this pseudo-binary intermetallic alloy with vanadium additions have not been fully investigated. Thus, the purpose of this work is to obtain information about the alloy performance related to mechanical properties and physical properties when the crystal structure is modified by the addition of vanadium atoms considering a substitutional mechanism.

\section{Experimental Procedures}

Alloys with nominal silicon concentration of 24 at.\% were alloyed with Mo and $\mathrm{V}$ elements (99.99\% purity) using arc-melting equipment, under argon atmosphere (Table 1 shows the nominal alloy compositions). The alloys were drop-cast into water-cooled copper molds. Resultant specimens were annealed at $1400^{\circ} \mathrm{C} / 24 \mathrm{~h}$ subsequently furnace cooled.

Metallographic polishing was carried out, using paper grinding and polishing up to alumina grade $0.05 \mu \mathrm{m}$; specimens were etched with Murakami's reagent (10 $\mathrm{mL}$ of distillated water and $10 \mathrm{~g}$ of Potassium Ferro cyanide ) for $1-2 \mathrm{~s}$. After that, samples were observed in an optical microscope equipped with IPA (image processing analysis) software as well in a Scanning Electron Microscope. Lattice parameters were calculated by X-ray diffraction technique using silicon powders as standard. Hardness evaluation were carried out in a Leco 300 MT microhardness tester using a load of $500 \mathrm{~g}$ with a holding time of $15 \mathrm{~s}$ each experiment was repeated ten times in order to obtain an acceptable standard deviation. Fracture toughness evaluation was carried out using the indentation method [12].

\section{Results and Discussion}

\subsection{Microstructure Analyses}

Microstructures of the samples with different $\mathrm{V}$ additions are presented in Figures 1 (a)-(d). It can be observed that alloys with low vanadium concentrations present a second phase precipitation which segregate mainly to the grain boundaries which can be observed in Figures 1(a)-(c), while in Figure 1(d) it is

Table 1. Nominal alloy composition and densities for the alloys with $\mathrm{V}$ additions.

\begin{tabular}{cccc}
\hline Si [at.\%] & Mo [at.\%] & V [at.\%] & $\rho\left[\mathrm{g} / \mathrm{cm}^{3}\right]$ \\
\hline 24.00 & 76.00 & 0.00 & 9.00035 \\
24.00 & 59.00 & 17.00 & 8.3562 \\
24.00 & 40.00 & 36.00 & 7.59464 \\
24.00 & 23.00 & 53.00 & 6.82052 \\
24.00 & 0.00 & 76.00 & 5.722 \\
\hline
\end{tabular}



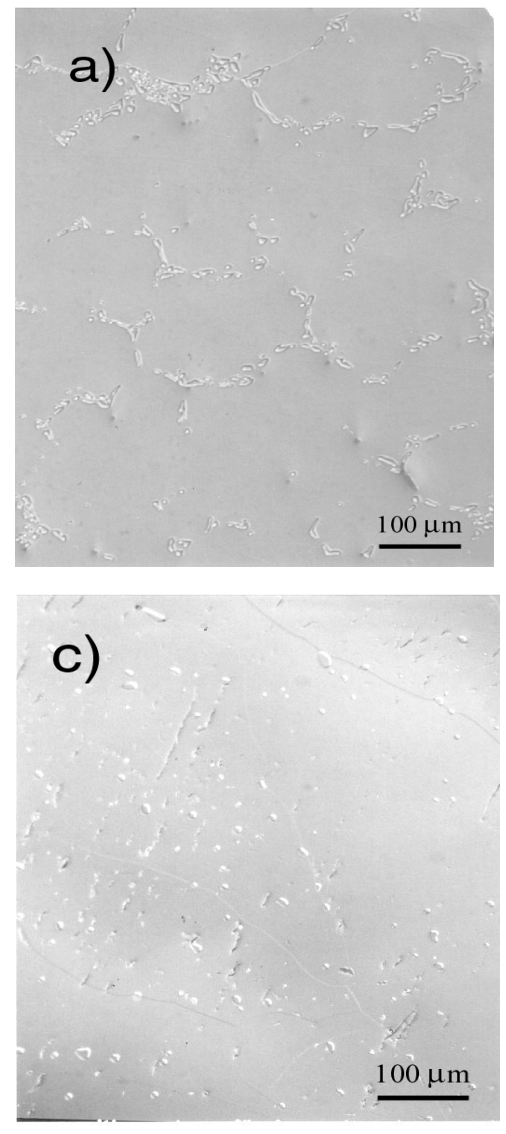

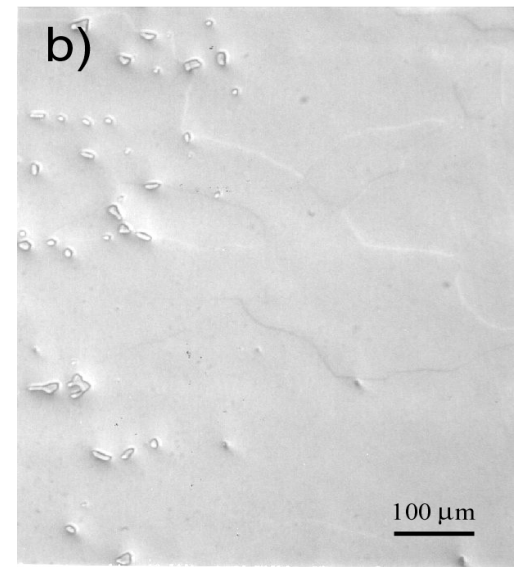

d)

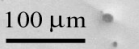

Figure 1. Microstructure of the alloys with different vanadium concentrations (a) 17, (b) 36, (c) 53, (d) 76 at.\% where it is observed that in figure d, scratches from crucible contamination.

observed a $\mathrm{V}_{3} \mathrm{Si}$ single phase structure where $\mathrm{A} 15$ structure is produced by a peritectic reaction [9] with vanadium is positioning in faces and silicon in the corner and center of the cubic structure. In this direction, area fraction analyses of second phase revealed a 3.0, 5.0 and 7.4 percent for samples with 17, 36 and $53 \mathrm{~V}$ at.\% respectively. Alloys surfaces without cracking were obtained in all range of compositions. Using the IPA software, morphological analyses reveals an average grain size of 195, 260 and $380 \mu \mathrm{m}$ respectively for the above mentioned alloys; evidently these grain sizes are produced due to the annealing treatment and the presence of the second phases that precipitate along the grain boundaries [3] [4] [5] as was mentioned in the area fraction analyses.

\subsection{X-Ray Diffraction Analyses}

X-ray diffraction patterns of the alloys are shown in Figure 2, where it can be observed for the case of the alloys with low vanadium content the apparition of the $\mathrm{Mo}_{5} \mathrm{Si}_{3}$ as secondary phase together with the $\mathrm{Mo}_{3} \mathrm{Si}$ (main phase), while the sample with 53 at.\% $\mathrm{V}$ presents the apparition of the $\mathrm{V}_{5} \mathrm{Si}$ as secondary phase, being $\mathrm{V}_{3} \mathrm{Si}$ the primary phase. The presence of the observed second phases can be attributed mainly to the silicon evaporation [5] carried out in the melting and 


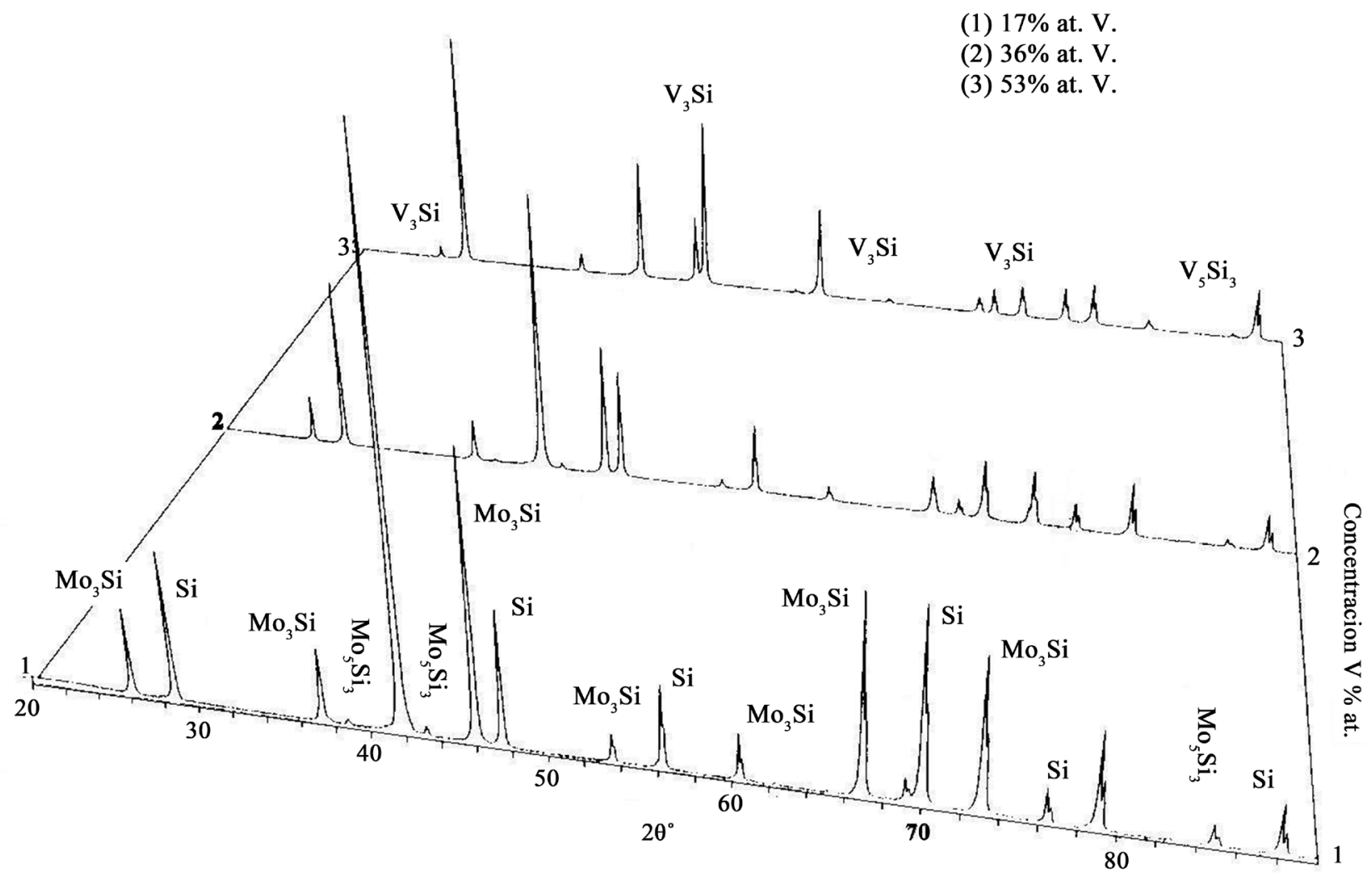

Figure 2. X-ray diffraction analyses of the samples after annealing. It is observed the silicon peaks that were used as standard for lattice parameter calculations.

heat treatment processes where the absence of silicon atoms generate the A15 structure transformation and for consequence formation of secondary phases [7] [8].

It is important to mention that these phases are in good agreement with the predictions of V-Mo-Si ternary alloys phase diagram.

\subsection{Physical Properties}

\subsubsection{Lattice Parameter Analysis}

The Goldschmidt radius of V $(1.33 \AA)$ is similar to that of Mo (1.37 $\AA)$ [13]. Therefore, the lattice discrepancy between Mo and $\mathrm{V}$ is only 3.56\%. In this way, in order to obtain the information related with the effect produced by the modification of the lattice parameter as a function of the $\mathrm{V}$ content in the $\mathrm{Mo}_{3} \mathrm{Si}$ alloy, in Figure 3 it is observed the plot of the numerical values of the lattice parameter obtained from X-ray diffraction analysis using silicon peaks as standard; as it was expected, it can be observed that the values diminishes when is increased the $\mathrm{V}$ atoms in the crystal structure.

Although, the size disparity for atomic radii is minimal, the lattice parameter calculated across the transition reflect a noticeable distortion then it is concluded that the occurred process is clearly substitutional [6], this phenomena it is attributed to the fact that vanadium forms chains of two atoms in faces of the A15 crystal structure, producing in this way the observed lattice reduction. 


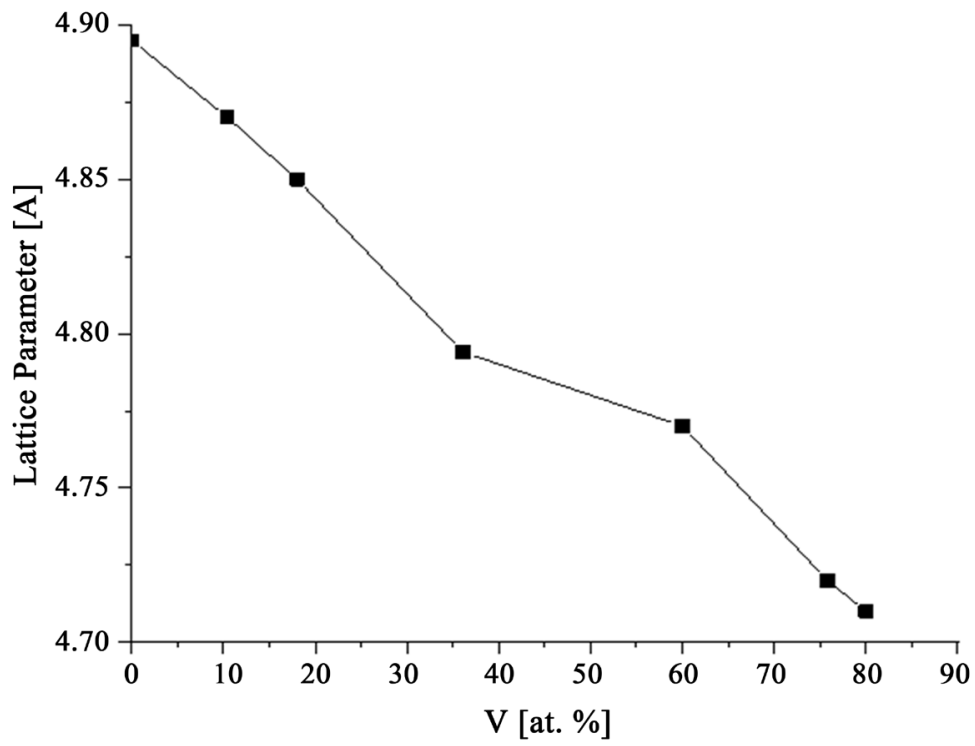

Figure 3. Lattice parameter as function of at. $\% \mathrm{~V}$ on the alloy $\mathrm{Mo}_{3} \mathrm{Si}$, with a change in slope value between 40 to $60 \mathrm{~V}$ at.\%.

\subsubsection{Density Evaluation}

The density evaluation was performed in order determine the possible existence of internal defects in the alloys by means of observe how much weight can be reduced after vanadium additions, since vanadium possesses lower atomic weight in comparison with molybdenum as much as 3.278 grams per mol, this information is very valuable since the specific application depend on it [4]. Under the knowledge that alloys were fabricated using a controlled atmosphere to avoid the contaminations presence such as oxygen and other contaminants that may provoke the vacancies concentration production, then the density reduction is produced exclusively due to the reduction of elemental atomic weight in crystal structure.

In Table 1 it is observed that reduction in density values are directly related to the substitution of molybdenum by vanadium atoms thus, taking in consideration the tendency values, it is observed that there are not noticeable variations along the different vanadium compositions, this information support the no formation of structural defects in the alloys such as micro porosity [7] [8] [9], which is the main cause to produce a detrimental behavior on the mechanical properties.

\subsection{Mechanical Properties}

\subsubsection{Hardness Analysis}

Figure 4 shows the plot of the microhardness for samples with different vanadium concentrations, it is observed that microhardness value decreases at the time that $\mathrm{V}$ concentrations increase, showing only a small variation for the final composition which can be attributed to the presence of a $\mathrm{V}_{3} \mathrm{Si}$ single phase.

Microhardness results have shown that vanadium addition on $\mathrm{Mo}_{3} \mathrm{Si}$ structure affect the mechanical behavior, diminishing its resistance. The main proposed 
mechanism for the hardness reduction is the minimal second phase precipitation which does not provide enough barriers for the dislocation mobility [9], accompanied with the fact that the grain size in the alloys it is considerable big enough to permit the easy dislocation mobility. So that, the hardness obtained in this alloy suggests that one potential application could be in parts exposed under moderated wear conditions [10], may be by using powder depositions techniques.

\subsubsection{Fracture Toughness Evaluation}

Figure 5 presents the curves of the values of fracture toughness against the different $\mathrm{V}$ concentrations. For lower $\mathrm{V}$ additions the value of fracture toughness keeps a constant value for additions lower than 36 at.\%, and for higher additions the fracture toughness value increases approximately 25 percent in comparison with the value reported for $\mathrm{Mo}_{3} \mathrm{Si}$ single phase [9].

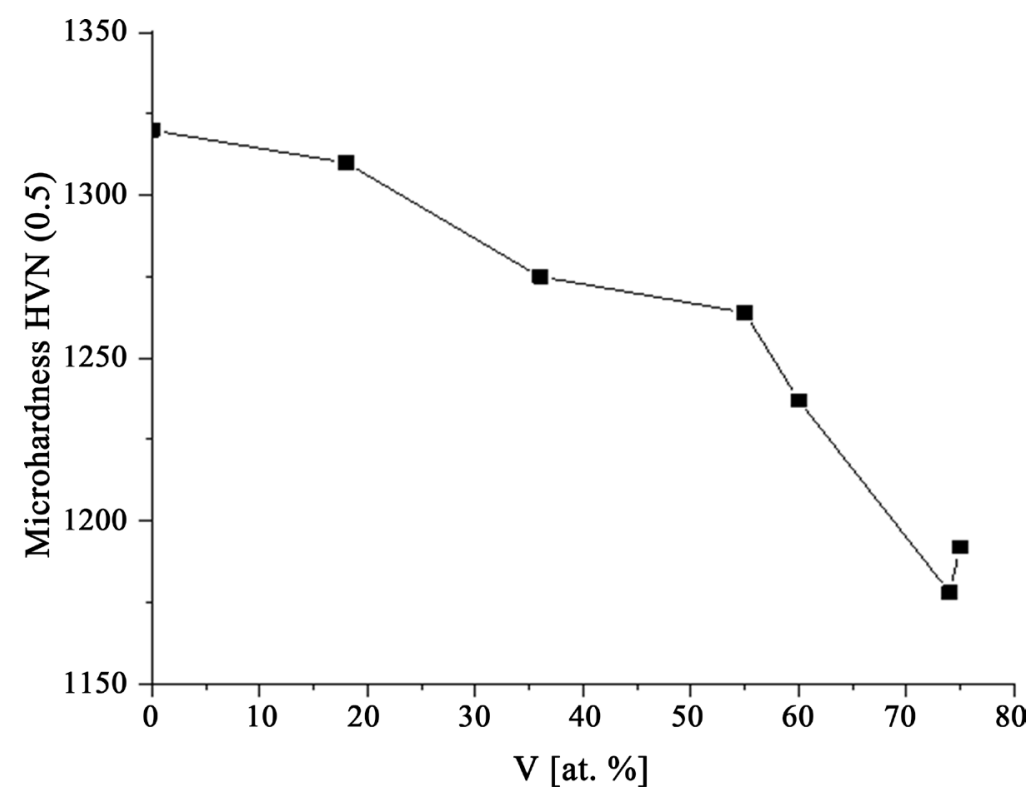

Figure 4. Plot of microhardness with different vanadium concentration.
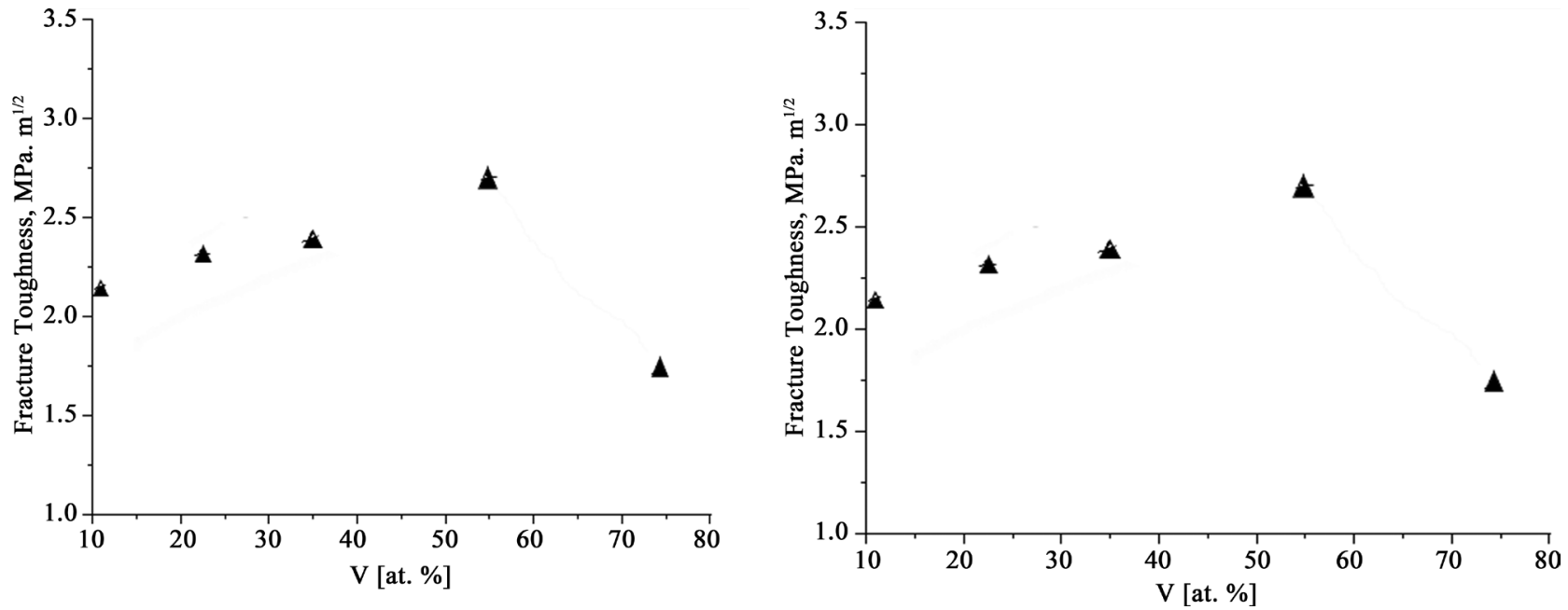

Figure 5. Plot of fracture Toughness as a function of $\mathrm{V}$ content showing an increment in value of $53 \mathrm{~V}$ at.\%. 
It is well known that defects such as porosity may cause increment in brittleness and this effect is produced generally by external contamination, in our case, after analyze the surface samples was observed that the alloys does not present this type of defects, hence the fracture toughness value it is not affected by these defects in detrimental way. Thus, the explanation for the increment in toughness is because the second phase apparition promotes the grain boundary reinforcement at this specific vanadium concentration [3]. Since the ductility in this intermetallic type alloys is very low, this results satisfy one of the intrinsic toughening approaches related with the reduction of the second phase dimensions with its corresponding grain boundary segregation.

\section{Conclusion}

Additions of $\mathrm{V}$ on $\mathrm{Mo}_{3} \mathrm{Si}$ matrix were produced successfully by arc melting technique, producing in the majority of the cases large grains with precipitates along the grain boundaries. Microhardness results have shown a decreasing behavior when $\mathrm{V}$ concentration is increased. Fracture toughness results have shown increased effect in samples with approximately $53 \mathrm{~V}$ at.\% attributed to the second phase precipitation. Lattice parameter analyses indicate a reduction, attributed to the incorporation of vanadium atoms inner the A15 structure, performing a substitutional mechanism. Densities values have shown a decreasing value, therefore, alloys can be considered for light applications. In general, the compound can be used in works with high temperature environments and requirements with considerable resistance.

\section{Acknowledgements}

The author is grateful to R. Guardian for technical assistance, and also sends thanks to going to ORNL for the use of their facilities in sample preparation. This research was supported by PRODEP-PTC-074 project.

\section{Conflicts of Interest}

The author declares no conflicts of interest regarding the publication of this paper.

\section{References}

[1] Vasudevan, A.K and Petrovic, J.J. (1992) A Comparative Overview of Molybdenum Disilicide Composites. Materials Science and Engineering: A, 155, 1-17. https://doi.org/10.1016/0921-5093(92)90308-N

[2] Petrovic, J.J. and Vasudevan, A.K. (1999) Key Developments in High Temperature Structural Silicides. Materials Science and Engineering: A, 261, 1-5. https://doi.org/10.1016/S0921-5093(98)01043-0

[3] Akinc, M., Meyer, M.K., Kramer, M.J., Thom, J.A., Huebsch, J.J. and Cook, B. (1999) Boron-Doped Molybdenum Silicides for Structural Applications. Materials Science and Engineering: A, 261, 16-23. https://doi.org/10.1016/S0921-5093(98)01045-4 
[4] Schneibel, J.H., Kramer, M.J. and Easton, D.S. (2002) A Mo-Si-B Intermetallic Alloy with a Continuous $\alpha$-Mo Matrix. Scripta Materialia, 46, 217-221. https://doi.org/10.1016/S1359-6462(01)01227-1

[5] Liu, C.T., Schneibel, J.H. and Heatherly, L. (1998) Processing, Microstructure, and Properties of Multiphase Mo Silicide Alloys. MRS Online Proceedings Library, 552, Article No. 621. https://doi.org/10.1557/PROC-552-KK6.2.1

[6] Sha, D.M. and Anton, D.L. (1992) Evaluation of Refractory Intermetallics with A15 Structure for High Temperature Structural Applications. Materials Science and Engineering: A, 153, 402-409. https://doi.org/10.1016/0921-5093(92)90228-S.

[7] Raj, S.V., Whittenberg, J.D., Zeumer, B. and Sauthoff, G. (1999) Elevated Temperature Deformation of $\mathrm{Cr}_{3}$ Si Alloyed with Mo. Intermetallics, 7, 743-755. https://doi.org/10.1016/S0966-9795(98)00095-8

[8] Raj, S.V. (1995) An Evaluation of the Properties of $\mathrm{Cr}_{3}$ Si Alloyed with Mo. Materials Science and Engineering: A, 201, 229-241. https://doi.org/10.1016/0921-5093(95)09767-8

[9] Rosales, I. and Schneibel, J.H. (2000) Stoichiometry and Mechanical Properties of $\mathrm{Mo}_{3}$ Si. Intermetallics, 8, 885-889. https://doi.org/10.1016/S0966-9795(00)00058-3

[10] Smith, L.S., Aindow, M. and Loretto, M.H. (1993) Dislocations and Slip Systems in $\mathrm{V}_{3}$ Si. MRS Online Proceedings Library, 288, 477-482. https://doi.org/10.1557/PROC-288-477

[11] Okada, S., Suda, T., Kamezaki, A., Hamano, K., Kudou, K., Takagi, K. and Lundstrom, T. (1996) Crystal Growth of Vanadium Silicides from High-Temperature Metal Solutions and Some Properties of the Crystals. Materials Science and Engineering. A, 209, 33-37. https://doi.org/10.1016/0921-5093(95)10093-8

[12] Zhu, J.H., Pike, L.M., Liu, C.T. and Liaw, P.K. (1999) Point Defects in Binary Laves Phase Alloys. Acta Materialia, 47, 2003-2018. https://doi.org/10.1016/S1359-6454(99)00090-7

[13] Laves, F. (1956) Theory of Alloy Phases. Philadelphia: American Society for Metals, 131-133. 